\title{
Influence of oxytocin infusion during oestrus and the early luteal phase on progesterone secretion and the establishment of pregnancy in ewes
}

\author{
D. C. Wathes ${ }^{1 *}$, V. J. Ayad ${ }^{1}$, C. L. Gilbert ${ }^{1 *}$, S. A. McGoff ${ }^{1}$ and \\ C. M. Wathes ${ }^{2} \dagger$ \\ ${ }^{1}$ Department of Anatomy, School of Medical Sciences, Bristol BS8 ITD, UK and ${ }^{2}$ Department of \\ Animal Husbandry, University of Bristol, Langford, Bristol BS18 7DU, UK
}

\begin{abstract}
Summary. In Experiment 1, an osmotic minipump containing oxytocin was implanted s.c. in ewes for 12 days beginning on Day 10 of the oestrous cycle, producing $\sim 100 \mathrm{pg}$ oxytocin $/ \mathrm{ml}$ in the plasma. Two days after the start of infusion, all ewes were injected with $100 \mu \mathrm{g}$ cloprostenol and placed with a fertile ram. At slaughter 22 days later, 9 $(75 \%)$ of the 12 control (saline-infused) ewes were pregnant compared with $1(11 \%)$ of the 9 ewes infused with oxytocin. In the control group, midcycle plasma concentrations of oxytocin were significantly higher in nonpregnant than in pregnant ewes.

In Experiment 2, an infertile ram was used throughout to avoid any possible effects of pregnancy and oxytocin infusions were given at different stages of the oestrous cycle. Otherwise the protocol was similar to that in Exp. 1. Oxytocin infusion during luteolysis and the early follicular phase had no effect on the subsequent progesterone secretion pattern, but infusions beginning the day before cloprostenol-induced luteolysis and lasting for 7 or 12 days and infusions beginning on the day of oestrus for 4 days all delayed the subsequent rise in plasma progesterone by $\sim 3-4$ days. In these animals, the cycle tended to be longer.

It was concluded that an appropriate oxytocin secretion pattern may be necessary for the establishment of pregnancy in ewes and that a high circulating oxytocin concentration during the early luteal phase delays the development of the young corpus luteum.
\end{abstract}

Keyrords: oxytocin; progesterone; sheep; pregnancy

\section{Introduction}

Oxytocin is a major product of the corpus luteum in ruminants (Wathes \& Swann, 1982), but its role during the oestrous cycle is far from certain. Whilst there is good evidence for an involvement in luteolysis (see Auletta \& Flint, 1988 and Wathes, 1989 for reviews), mean circulating oxytocin concentrations are highest in the early to midluteal phase (Webbet al., 1981; Schams et al., 1982) and receptor concentrations in the reproductive tract peak on the day of oestrus (Sheldrick \& Flint, 1985; Ayad \& Wathes, 1989; Ayad et al., 1990a). Ewes actively immunized against oxytocin failed to establish pregnancy when mated with a fertile ram (Wathes et al., 1989), suggesting that oxytocin may have an additional, uncharacterized action(s) in the regulation of fertility. In cows, daily oxytocin injections in the early part of the cycle interfere with the normal development of the corpus luteum (Armstrong \& Hansel, 1959), although similar protocols in ewes have not had a

\footnotetext{
*Present address: AFRC Institute of Animal Physiology \& Genetics Research, Babraham Hall, Cambridge CB2 4AT, UK.

†Present address: AFRC Institute of Engineering Research, Wrest Park, Silsoe, Bedford MK45 4HS, UK.
} 
major influence on luteal function (Milne, 1963; Hatjiminaoglou et al., 1979). In contrast, oxytocin infusion starting in the midluteal phase extends luteal lifespan, presumably by interfering with the mechanisms normally regulating luteolysis (Flint \& Sheldrick, 1985).

The purpose of the first experiment reported here was to see whether oxytocin infusion influenced the establishment of pregnancy in ewes. In the second experiment, we investigated the effect of treatment with oxytocin at different stages in the oestrous cycle on luteal function.

\section{Materials and Methods}

Two experiments were conducted during the $1988 / 89$ breeding season, using mature Clun Forest ewes kept at pasture, with hay provided as a supplementary feed.

Preparation of osmotic minipumps. Both experiments involved infusion of oxytocin via Alzet minipumps (Alza Corporation, Palo Alto, CA, USA) filled with either vehicle (saline, $0.9 \% \mathrm{w} / \mathrm{v} \mathrm{NaCl}$ containing $0.01 \%$ acetic acid) or oxytocin (Hoechst, Frankfurt, West Germany) dissolved in the same vehicle. Solutions were filtered $(0.22 \mu \mathrm{m}$ filters, Millipore Corp., Bedford, MA, USA) before use and loaded into the pumps under sterile conditions. In Exp. 1 they were stored desiccated overnight at $44^{\circ} \mathrm{C}$ before insertion. The following morning they were incubated for $4 \mathrm{~h}$ at $37^{\circ} \mathrm{C}$ in $15 \mathrm{ml}$ sterile saline and then implanted s.c. over the chest wall behind the left elbow under local anaesthesia. In Exp. 2 pumps were incubated overnight in sterile saline at $4^{\circ} \mathrm{C}$ and then transferred to fresh saline for incubation for $1 \mathrm{~h}$ at $37^{\circ} \mathrm{C}$ the following morning before implantation s.c. on the dorsal surface of the neck.

Experiment 1. Twenty-one ewes were divided at random into 3 treatment groups: (1) no infusion $(n=7),(2)$ vehicle infusion ( $n=5)$ and (3) oxytocin infusion ( $n=9,1.25 \mathrm{mg}$ oxytocin $/ \mathrm{ml}$ in Alzet minipumps $2 \mathrm{ML2}$ ). The start of the treatment was phased over 7 days to avoid all animals coming into oestrus at the same time. All ewes were run initially with a raddled, vasectomized ram and raddle marks were noted daily. Ten days after oestrus, minipumps were implanted and 2 days later (Day 12 of the cycle) all ewes were given a single i.m. injection of $100 \mu \mathrm{g}$ cloprostenol (prostaglandin F-2 $\alpha$ analogue (PG); Coopers Animal Health Ltd. Crewe, Cheshire, UK) and transferred to a paddock containing a raddled, fertile ram. The pumps were left in place for 12 days and then removed under local anaesthesia. After a further 12 days (22 days after the PG injection), ewes were slaughtered and the reproductive tracts were removed. Structures visible on the ovaries were noted and the tracts were opened to examine the number, size and apparent viability of any embryos.

Blood samples $(10 \mathrm{ml})$ were collected by jugular venepuncture 3 times a week from the first oestrus until PG treatment and thereafter daily. Following centrifugation at $4^{\circ} \mathrm{C}$ and $2000 \mathrm{~g}$ separate aliquants of plasma were stored frozen at $-80^{\circ} \mathrm{C}$ for oxytocin and at $-20^{\circ} \mathrm{C}$ for progesterone for subsequent estimation by radioimmunoassay (RIA).

Experiment 2. The protocol was similar to that of Exp. 1, but an infertile ram was used throughout to avoid any pregnancy $\times$ treatment interactions. Ewes $(n=28)$ were assigned at random to different treatment groups as they came into oestrus naturally, such that the start of treatment was phased over 15 days. All animals received an injection of PG on Day 12 of the oestrous cycle. The treatment groups are illustrated in Fig. 1. Group 4 ewes received Alzet Minipumps 2ML2 containing $1.23 \mathrm{mg}$ oxytocin/ml; groups 2, 3,5 and 6 received Alzet Minipumps 2001 containing $6.15 \mathrm{mg}$ oxytocin $/ \mathrm{ml}$. The smaller pumps had a slower flow, so these concentrations produced the same net release of oxytocin. All of the animals in Groups 1-5 were slaughtered 22 days after the PG injection for examination of their reproductive tracts and ovaries. A further 3 ewes (Group 6) received an oxytocin infusion from Day 11 of the cycle, but were slaughtered 2 days after PG for measurement of oxytocin receptor concentrations. The oviducts, endometrium and myometrium were dissected out and processed as described by Ayad \& Wathes (1989) and Ayad et al. (1990a).

Blood samples were collected 3 times a week by jugular venepuncture from the first oestrus until pump insertion for progesterone RIA. Thereafter, blood samples were collected daily for measurement of progesterone and oxytocin.

Radioimmunoassays. Progesterone measurements were performed on $0 \cdot 25-\mathrm{ml}$ aliquants of plasma using petroleum-ether extraction as described by Wathes et al. (1986). The detection limit was $16 \mathrm{pg} /$ tube, the extraction efficiency was $74 \pm 1 \cdot 3 \%$ and the intra- and interassay coefficients of variation were $11 \cdot 1$ and $14 \cdot 1 \%$, respectively.

Oxytocin was measured after extraction of 4-ml plasma samples on C18 cartridges (Jones Chromatography Ltd, Hengoed, Mid-Glamorgan, UK) with minor modifications to a method described by Wathes et al. (1986). Columns were prewetted with $3 \mathrm{ml} 80 \%$ acetonitrile (ACN) in $0 \cdot 1 \%$ trifluoroacetic acid (TFA) followed by $5 \mathrm{ml} \mathrm{H}_{2} \mathrm{O}$. Plasma samples were prepared by dilution in an equal volume of phosphate buffer $\left(1.4 \mathrm{~g} \mathrm{Na}_{2} \mathrm{HPO}_{4} .2 \mathrm{H}_{2} \mathrm{O}, 0 \cdot 26 \mathrm{~g} \mathrm{KH}_{2} \mathrm{PO}_{4}\right.$, $8.65 \mathrm{~g} \mathrm{NaCl} / \mathrm{l})$ and centrifugation for $10 \mathrm{~min}$ at $4{ }^{\circ} \mathrm{C}$ and $1500 \mathrm{~g}$. They were then applied slowly to the columns and washed through with $20 \mathrm{ml} 10 \% \mathrm{ACN}$ in $0.1 \%$ TFA. Oxytocin was eluted with $3 \mathrm{ml} 80 \% \mathrm{ACN}$ in $0.1 \%$ TFA. The $A C N$ was removed by centrifugation in a rotary film evaporation centrifuge set at $35^{\circ} \mathrm{C}$ (Univap Uniscience, Cambridge, UK) and the remaining extract was freeze dried. The extract was redissolved in $0.5 \mathrm{ml}$ phosphate buffer containing $1 \mathrm{mg} / \mathrm{ml}$ bovine serum albumin (Sigma Chemical Co., Poole, Dorset, RIA grade). Aliquants of $50 \mu \mathrm{l}$ of this solution were measured in an RIA for oxytocin using antiserum 85/2 (Gilbert et al., 1991). Separation was achieved 


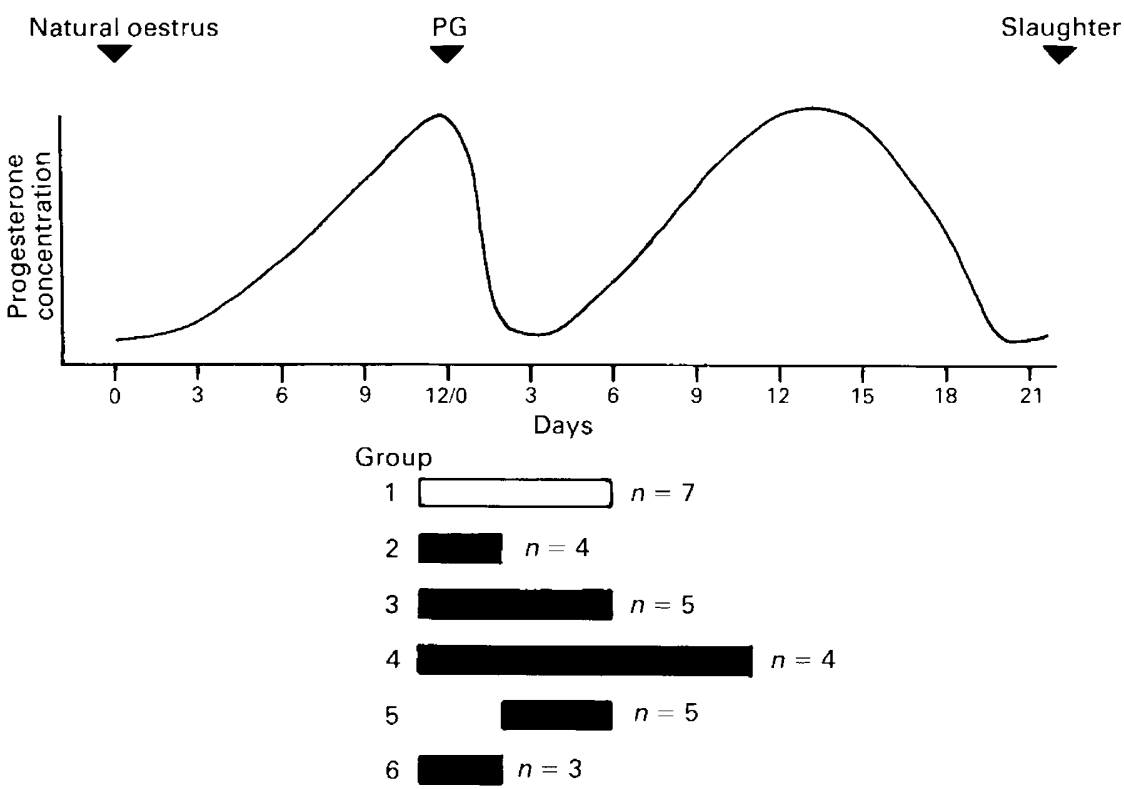

Fig. 1. Diagram to show protocol for ewes in Exp. 2: time of ( $\square$ ) saline infusion, ( $\square$ ) of oxytocin infusion, PG shows the injection of $100 \mu \mathrm{g}$ cloprostenol i.m. given to all ewes on Day 12 of the cycle. The treatment groups were: (1) controls, (2) oxytocin infusion from Day 11 of the cycle until $40 \mathrm{~h}$ after PG treatment, (3) oxytocin infusion from Day 11 for 7 days, (4) oxytocin infusion from Day 11 for 12 days, (5) oxytocin infusion on Days 2-6 after PG and (6) oxytocin infusion from Day 11. Group 6 ewes were slaughtered 2 days after PG, all the others 22 days after $P G$ as shown.

using $0.15 \mathrm{ml}$ anti-rabbit-precipitating antibody (UCB BioProducts, Belgium). The sensitivity of the assay was $0.5 \mathrm{pg}$ per tube and the intra- and interassay coefficients of variation were 8.5 and $2.8 \%$, respectively.

Receptor measurements. Concentrations of oxytocin receptors in membrane fractions were estimated by incubating a single, saturating concentration of ${ }^{3} \mathrm{H}$ ]oxytocin (NEN, Stevenage, Herts, UK) with a single concentration of membrane protein as described by Ayad \& Wathes (1989) and Ayad et al. (1990a). Specific binding was measured on 2 separate occasions for each sample and the mean value was obtained. The interassay coefficient of variation was $13.9 \%$.

Statistical analysis. The design of both experiments was of repeated measures over time, with oxytocin infusion as the experimental factor. All data were analysed by ANOVA and means were compared using the least significant difference for the time $\times$ oxytocin or time $\times$ pregnancy interactions. Two analyses were undertaken for Exp. 1: (i) the effect of pregnancy on oxytocin profiles in the control animals, Groups 1 and 2; and (ii) the effect of oxytocin infusion on progesterone profiles, with the control animals subdivided into pregnant and nonpregnant groups. A single analysis was performed in Exp. 2, the effect of oxytocin infusion on progesterone profiles in Groups 1-5.

\section{Results}

\section{Experiment 1}

There were no apparent differences between Group 1 (no infusion) and Group 2 (vehicle infusion), so these animals were considered as a single control group. All animals (control and oxytocin-infused) had received raddle marks by either the second or third morning after PG injection. At slaughter (22 days after PG), 9 of the 12 control ewes were pregnant $(75 \%)$. Their reproductive organs each contained $1-3$ corpora lutea $(C L)(2 \cdot 1 \pm 0 \cdot 20)$ and $1-3$ viable embryos 

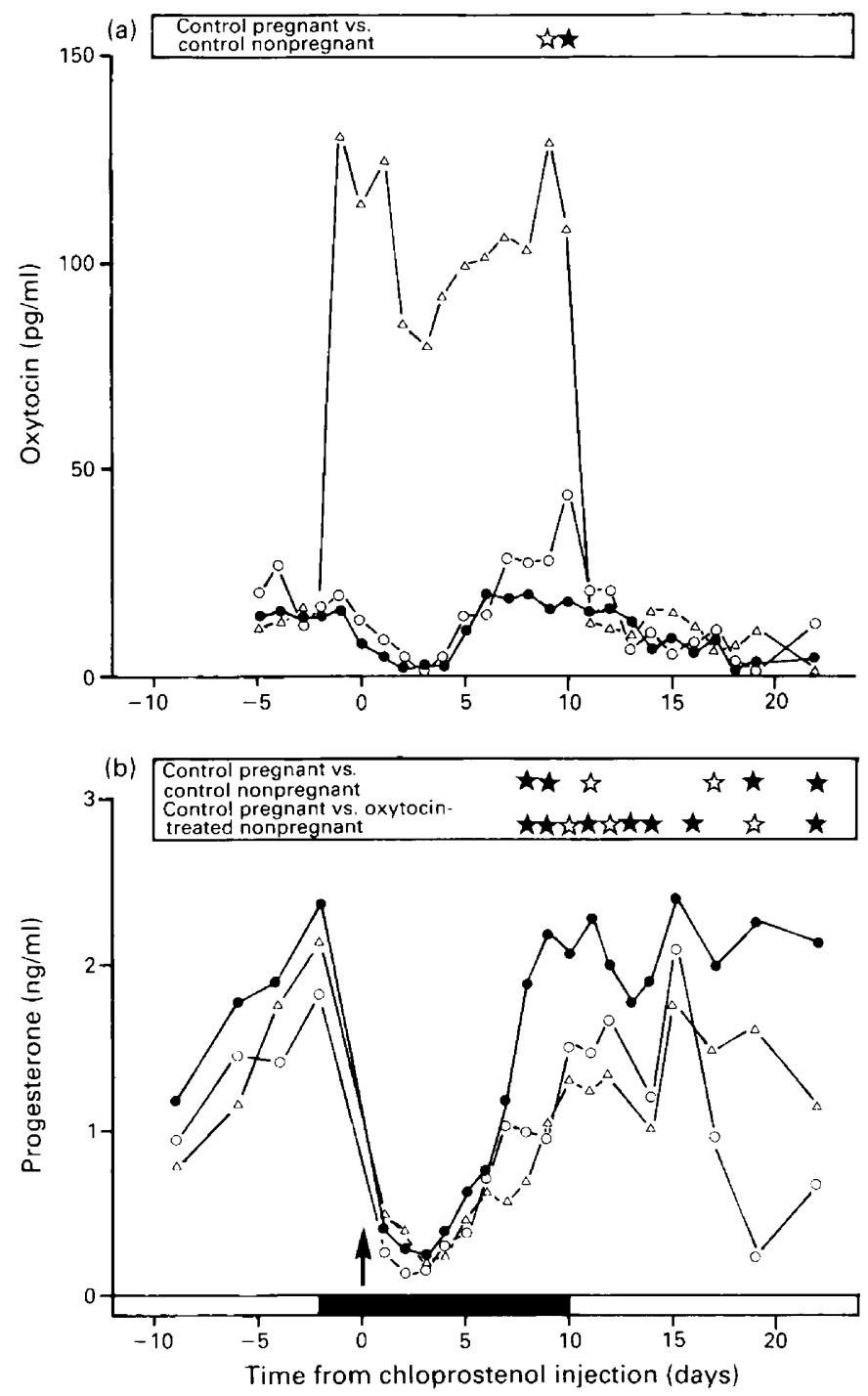

Fig. 2. Concentrations of (a) oxytocin and (b) progesterone in control ewes which conceived $(\boldsymbol{O}, n=9)$ or did not conceive $(\bigcirc, n=3)$ and in oxytocin-infused ewes which did not conceive $(\triangle, n=8)$, Exp. 1; ( $)$ infusion period. Data are aligned around the PG injection (Day 0, arrow) given on Day 12 of the oestrous cycle. All ewes showed oestrus $2-3$ days after injection. Points marked with an asterisk were significantly different (ANOVA) at $P<0.05$ 㚎 or $P<0.01$ $\star$ (a) in comparison between pregnant and nonpregnant control ewes and (b) in comparison with the pregnant control ewes. Data are means, with standard errors omitted for clarity.

$(1.9 \pm 0.20)$ and one ewe had one additional degenerating embryo. The 3 nonpregnant control ewes had all reovulated. In contrast, only 1 of the 9 oxytocin-infused ewes was pregnant at slaughter $(11 \%)$, with $2 \mathrm{CL}$ and 1 embryo. Of the remaining 8 nonpregnant ewes, only 2 had recently reovulated. The ovaries of the others contained either mature ( $n=4$ ewes) or regressing ( $n=2$ ewes) CL. These data indicate that the lifespan of the CL was maintained in the oxytocininfused ewes, even though no signs of degenerating conceptuses were found in their reproductive tracts. 

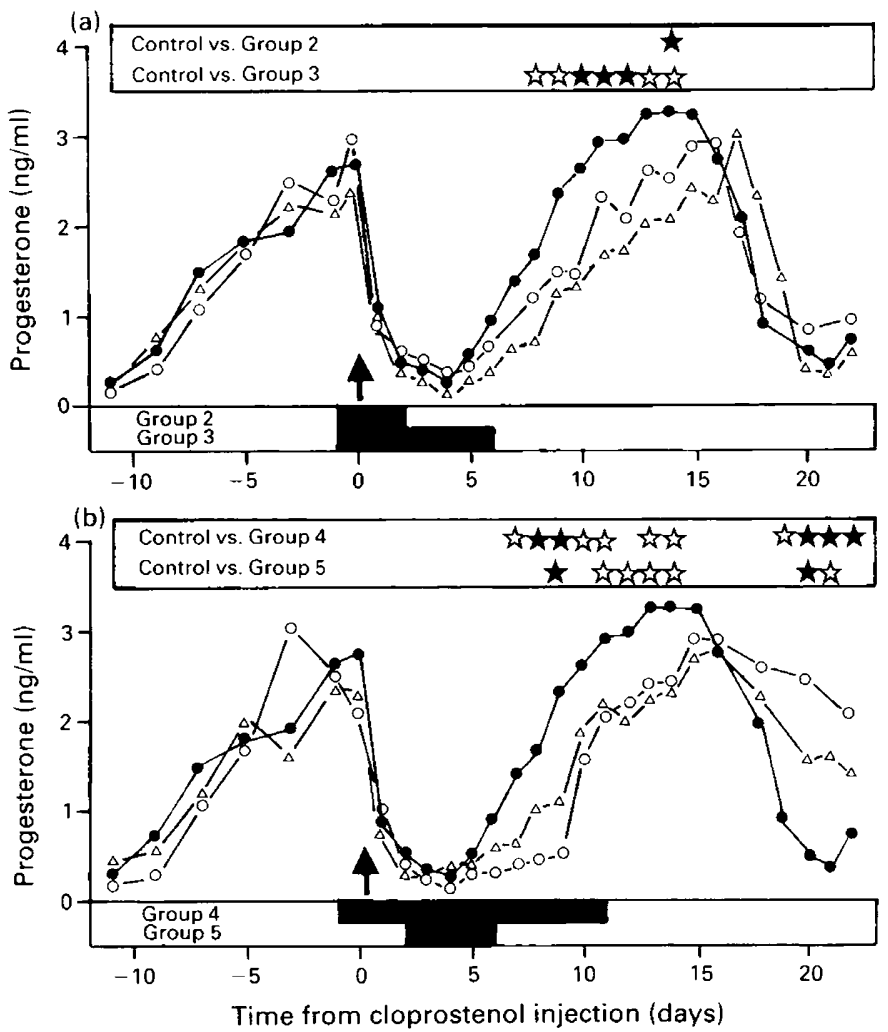

Fig. 3. Progesterone concentrations in ewes in Exp. 2 treated with oxytocin at different times as shown by ( ) (a) and (b) Group 1, control $(\Theta, n=7)$, (a) Group $2(O, n=5)$, Group $3(\triangle$, $n=5)$, (b) Group $4(\bigcirc, n=4)$, Group $5(\triangle, n=5)$. Data are aligned around the PG injection (Day 0, arrow) given on Day 12 of the oestrous cycle. Points marked with an asterisk were significantly different (ANOVA) in comparison with the control ewes at $P<0.05$ is or $P<0.01$ $\star$ Data are means, with standard errors omitted for clarity.

Because of the likelihood that pregnancy would have influenced the endocrine profiles, it was considered appropriate to subdivide the control and oxytocin-infused groups into pregnant and nonpregnant animals for analysis of the hormone data. All results are presented in relation to the day of the PG injection (Day 0 ), which was either 2 or 3 days before oestrus. The oxytocin infusions produced continuously raised oxytocin concentrations in all ewes (Fig. 2a). There was considerable daily variation in the exact concentration, but all values were within the range $40-252 \mathrm{pg} / \mathrm{ml}$. Values from the one oxytocin-infused ewe which conceived have been omitted from Fig. 2 for clarity, but were within the same range $(65-144 \mathrm{pg} / \mathrm{ml})$. A comparison between the pregnant and nonpregnant control ewes showed that the luteal-phase oxytocin concentrations tended to be higher in the control animals which did not conceive, with significant differences on Days 9 and 10 (time $\times$ pregnancy interaction, $P<0.05$ ), whereas luteal-phase progesterone concentrations tended to be lower (Fig. 2b), with significant differences on Days 8,9 and 11 (time $\times$ oxytocin interaction, $P<0.001$, Fig. 2). In the nonpregnant oxytocin-infused ewes, the progesterone concentrations rose more slowly and reached lower plateaux than in the pregnant controls, differences being significant from Day 8 onwards (Fig. 2b). The prolongation of the luteal phase in these animals was reflected in the maintenance of progesterone secretion beyond Day 17 . In the one pregnant, oxytocin-infused animal, progesterone concentrations also rose slowly, but they were similar to those in pregnant control ewes by Day 11 after PG (data not shown). 


\section{Experiment 2}

The oxytocin infusions were timed to provide high oxytocin concentrations during luteolysis and the early follicular phase only (Group 2); luteolysis and throughout the periovulatory period (Group 3); luteolysis, the periovulatory period and early luteal phase (Group 4); and from shortly before ovulation for 4 days (Group 5). The plasma oxytocin concentrations produced by the pumps during these times were within the same range as for Exp. 1.

Of the 25 ewes, 20 had received raddle marks by the second or third morning after PG injection. Of the remaining 5 animals, 2 were noted on the fourth day and 3 were not raddled at all, but these animals were distributed in each of Groups 1,3,4 and 5. ANOva analysis revealed significant differences between the progesterone profiles of the 5 groups $(P<0.001)$ (Fig. 3). Progesterone concentrations increased more slowly in each of Groups 3, 4 and 5, with a delay of $\sim 3-4$ days compared with the control ewes. Although progesterone concentrations in Group 2 tended to be slightly lower than in controls, the difference was significant only on Day 14 . However, peak progesterone concentrations were not different between groups $(3 \cdot 3 \pm 0 \cdot 20,2.9 \pm 0 \cdot 53,2 \cdot 5 \pm 0 \cdot 22$, $2.9 \pm 0.47$ and $2.7 \pm 0.46 \mathrm{ng} / \mathrm{ml}$ for Groups $1-5$, respectively). In Groups 4 and 5 , luteal regression was also clearly delayed (Fig. 3b). Whereas all (7/7) of the control ewes had reovulated at slaughter, this was not the case for any of the oxytocin-treated groups; $3 / 5(60 \%), 2 / 5(40 \%), 1 / 4(25 \%)$ and $2 / 5(40 \%)$ had reovulated in Groups $2-5$, respectively. Eleven of the oxytocin-treated animals still had mature or regressing CL in their ovaries, but in only one animal in Group 2 did the CL still present appear to be cystic.

The ovaries of the 3 ewes in Group 6 slaughtered 2 days after cloprostenol injection all contained regressing corpora lutea. The concentrations of oxytocin receptor in the oviduct, endometrium and myometrium were $91 \pm 12,518 \pm 104$ and $419 \pm 73 \mathrm{fmol} / \mathrm{mg}$ protein, respectively $(x \pm$ sem). These are within the range reported for oestrous ewes by Ayad \& Wathes (1989).

\section{Discussion}

The treatment regimens described provided a consistent model which could be used to examine the effect of oxytocin infusion around the time of ovulation and the early luteal phase in unrestrained ewes. The Alzet minipumps produced a high plasma oxytocin concentration throughout the time they were in place, $92 \%$ of plasma samples being within $40-180 \mathrm{pg} / \mathrm{ml}$. Whilst this is higher than the mean values found during the luteal phase in control ewes, such concentrations are frequently reached during the peaks of plasma oxytocin recorded at luteolysis (Flint \& Sheldrick, 1983; Hooper et al., 1986; Wathes et al., 1986). However, the consistently high oxytocin concentrations produced by the pumps clearly differed from the physiological pattern of release throughout much of the cycle: long pulses of 1-3 h normally occur during luteal regression (Flint \& Sheldrick, 1983; Hooper et al., 1986; Wathes et al., 1986) whereas low-amplitude, short pulses of 1-4 min occur at oestrus (Gilbert et al., 1991). Despite the high oxytocin concentrations, there was no evidence for down regulation of the oxytocin receptor during the oestrous period, as the 3 infused ewes killed at oestrus 2 days after PG injection all had uterine receptor measurements at the high end of the normal range for oestrous ewes. Similar results have been reported by Flint $\&$ Sheldrick (1985).

The prostaglandin treatment was necessary to induce luteal regression, as oxytocin infusion alone starting in the midluteal phase inhibits luteolysis in both sheep (Flint \& Sheldrick, 1985) and cows (Gilbert et al., 1989). As shown by Flint \& Sheldrick (1985), exogenous cloprostenol overrides this inhibition; all ewes so treated experienced immediate luteal regression and nearly all showed oestrus within 2-3 days of treatment. As raddle marks were only noted on a daily basis, it was not possible to give an accurate measure of the time from treatment to the onset of oestrus in the various groups, but there was no major shift in the timing of the oestrus in association with the oxytocin infusion.

The major conclusion from Exp. 1 was that oxytocin infusion could block the establishment of pregnancy. The tracts were not examined until 20 days after oestrus, so we do not know at what 
stage the pregnancies failed. Injections of oxytocin around the time of oestrus increased electromyographic activity throughout the reproductive tract (oviduct, uterus and cervix) for $\sim 5-20 \mathrm{~min}$ (Gilbert \& Wathes, 1989; E. L. Matthews, C. Walker \& V. J. Ayad, unpublished observations). One possibility is that oxytocin infusion acts on the reproductive tract musculature to interfere with sperm transport and prevent fertilization. Interaction with oxytocin receptors in the oviduct (Ayad et al., 1990a, b) could also influence the rate of egg or embryo transport. In the oxytocin-infused animals, the plasma progesterone concentrations rose more slowly after oestrus than in the controls and other workers have shown that low progesterone concentrations in the early luteal phase are detrimental to embryo survival, probably via an effect on the uterine environment (Wilmut et al., 1985; Ashworth et al., 1989). In a previous experiment (Wathes et al., 1989), we found that active immunization against oxytocin also prevented ewes from establishing pregnancy and these animals were shown to have raised gonadotrophin concentrations. It is clear that oxytocin has the potential to influence fertility in a number of ways and further work is necessary to establish which are most important.

Additional evidence for involvement of oxytocin in fertility was provided by Exp. 1, which showed that circulating oxytocin concentrations were higher in midcycle in the control ewes which failed to conceive. As the oxytocin profile appeared to differ also in the previous cycle before mating, this could not be attributable to an effect of pregnancy. This result must be regarded as preliminary, as only 3 animals were involved, but the slightly raised oxytocin concentrations occurring naturally may have had an adverse effect on fertility. Alternatively, they could have been the symptom of some other problems associated with luteal malfunction. We have shown previously that gonadotrophin-releasing hormone $(\mathrm{GnRH})$-stimulated anoestrous ewes have significantly higher plasma oxytocin concentrations in the early luteal phase if animals do not receive a 7-day progesterone priming (Hunter et al., 1989).

The results of Exp. 1 suggested that oxytocin infusions could inhibit luteal development. However, interpretation of these results was confounded by the difference in pregnancy rate between control and treated ewes. Therefore, Exp. 2 was performed to examine the effect of oxytocin infusion at different stages of the oestrous cycle on progesterone concentrations in unmated ewes. This showed that oxytocin infusion delayed the rise in progesterone following oestrus by $\sim 3-4$ days. One explanation could be that oxytocin had delayed ovulation, but preliminary results from a subsequent experiment in which ewes were slaughtered on Day 2 after oestrus do not support this hypothesis (D. C. Wathes, V. J. Ayad \& E. L. Matthews, unpublished observations). The data from the ewes in Group 2 showed that oxytocin infusion during the follicular phase alone had little effect on the subsequent progesterone profile. It appears, therefore, that the influence was on the young corpus luteum. It is well established that daily oxytocin injections between Days 3 and 6 of the cycle have an adverse effect on corpus luteum development in cows (Armstrong \& Hansel, 1959; Hansel \& Wagner, 1960; Staples et al., 1961; Tsang et al., 1990). Such treatment resulted in reduced plasma progesterone concentrations from about Day 6 onwards and in many cases also caused the formation of large, fluid-filled, cystic corpora lutea. In these experiments, the majority of animals treated in this way returned to oestrus prematurely and oxytocin was probably causing luteal regression by stimulating endometrial secretion of PGF-2 $\alpha$ (Oyedipe et al., 1984). However, previous work in ewes has been less convincing. Neither Milne (1963) nor Schreiber \& Milvae (1988) were able to influence the length of the oestrous cycle in ewes by oxytocin injections at various stages of the cycle, although Hatjiminaoglou et al. (1979) did cause premature luteal regression in 2 of 8 ewes given daily oxytocin injections between Days 0 and 7. This treatment also resulted in a lower luteal weight on Day 14.

Using the protocol described in the present study, only one ewe returned to oestrus prematurely after oxytocin infusion throughout the early luteal phase; the longest infusions terminating on Day 9 of the cycle (some days before the anticipated onset of luteolysis) tended to increase cycle length. A possible explanation for the delayed regression could be the need to have an increased progesterone concentration for a minimum of 7-10 days before the endometrium can synthesize 
both oxytocin receptors and PGF-2 $\alpha$, as suggested by McCracken et al. (1984). However, our previous studies into the mechanism of luteolysis in GnRH-treated anoestrous ewes (Hunter et al., 1989 ) indicated that an apparently normal type of oxytocin-PGF-2 $\alpha$ interaction can cause premature luteal regression after only 2-3 days of high progesterone.

In conclusion, oxytocin infusion during ovulation and the early luteal phase prevents ewes from becoming pregnant and delays the rise in progesterone secretion by the corpus luteum. These results suggest that an appropriate oxytocin secretion pattern may be necessary in the establishment of pregnancy.

We thank Mr G. Davies for care of the animals; Hoechst (Frankfurt, W. Germany) for donation of the oxytocin; and Mrs J. Skinner and Mrs J. Hood for secretarial assistance. The work was supported by grants from the AFRC and Wellcome Trust.

\section{References}

Armstrong, D.T. \& Hansel, W. (1959) Alteration of the bovine estrous cycle with oxytocin. J. Dairy Sci. 42, $533-542$.

Ashworth, C.J., Sales, D.I. \& Wilmut, I. (1989) Evidence of an association between the survival of embryos and the periovulatory plasma progesterone concentration in the ewe. J. Reprod. Fert. 87, 23-32.

Auletta, F.J. \& Flint, A.P.F. (1988) Mechanisms controlling corpus luteum function in sheep, cows, non human primates and women especially in relation to the time of luteolysis. Endocr. Rev. 9, 88-105.

Ayad, V.J. \& Wathes, D.C. (1989) Characterisation of endometrial and myometrial oxytocin receptors in the non-pregnant ewe. $J$. Endocr. 123, 11-18.

Ayad, V.J., McGoff, S.A. \& Wathes, D.C. (1990a) Oxytocin receptors in the oviduct during the oestrous cycle of the ewe. $J$. Endocr. 124, 353359.

Ayad, V.J., Guldenaar, S.E.F. \& Wathes, D.C. (1990b) Localization of oxytocin receptors in the uterus and oviduct of the oestrous ewe. J. Physiol. 426, 26P.

Flint, A.P.F. \& Sheldrick, E.L. (1983) Evidence for a systemic role of ovarian oxytocin in luteal regression in sheep. J. Reprod. Fert. 67, 2 [5-225.

Flint, A.P.F. \& Sheldrick, E.L. (1985) Continuous infusion of oxytocin prevents induction of uterine oxytocin receptor and blocks luteal regression in ewes. J. Reprod. Fert. 75, 623631.

Gilbert, C.L. \& Wathes, D.C. (1989) Changing patterns of electromyographic (EMG) activity in the oviduct of the ewe during the oestrous period and its sensitivity to administered oxytocin. J. Reprod. Fert., Abstr. Ser. 4, 21.

Gilbert, C.L., Lamming, G.E., Parkinson, T.J., Flint, A.P.F. \& Wathes, D.C. (1989) Oxytocin infusion from Day 10 after oestrus extends the luteal phase in non-pregnant cattle. J. Reprod. Fert. 86, 203210.

Gilbert, C.L., Jenkins, K. \& Wathes, D.C. (1991) Pulsatile release of oxytocin into the circulation of the ewe during oestrus and mating and in the early luteal phase. J. Reprod. Fert. 91, 337-346.

Hansel, W. \& Wagner, W.C. (1960) Luteal inhibition in the bovine as a result of oxytocin injections, uterine dilatation, and intrauterine infusions of seminal and preputial fluids. J. Dairy Sci. 43, 796805.

Hatjiminaoglou, I., Alifakiotis, T. \& Zervas, N. (1979) The effect of exogenous oxytocin on oestrous cycle length and corpus luteum lysis in ewes. Annals Biol. anim. Biochim. Biophys. 19, 355-365.

Hooper, S.B., Watkins, W.B. \& Thorburn, G.D. (1986) Oxytocin, oxytocin-associated neurophysin and prostaglandin $F 2_{a}$ concentrations in the uteroovarian vein of pregnant and non-pregnant sheep. Endocrinology 119, 2590-2597.

Hunter, M.G., Ayad, V.J., Gilbert, C.L., Southee, J.A. \& Wathes, D.C. (1989) The role of prostaglandin F-2 $\alpha$ and oxytocin in the regression of $\mathrm{GnRH}$-induced abnormal corpora lutea in anoestrous ewes. $J$. Reprod. Fert. 85, 55I-561.

McCracken, J.A., Schramm, W. \& Okvlicz, W.C. (1984) Hormone receptor control of pulsatile secretion of $\mathrm{PGF}_{2 \alpha}$ from the ovine uterus during luteolysis and its abrogation in early pregnancy. Anim. Reprod. Sci. 7, 31-55.

Milne, J.A. (1963) Effects of oxytocin on the oestrous cycle of the ewe. Aust. vet. J. 39, 51-52.

Oyedipe, E.O., Gustafsson, B. \& Kindahl, H. (1984) Blood levels of progesterone and 15-keto-13, 14dihydro prostaglandin $\mathbf{F}_{2 u}$ during the estrous cycle of oxytocin-treated cows. Theriogenology 22, 329-340.

Schams, D., Lahlou-Kassi, A. \& Glatzel, P. (1982) Oxytocin concentrations in peripheral blood during the oestrous cycle and after ovariectomy in two breeds of sheep with high and low fecundity. $J$. Endocr. 92, 9-13.

Schreiber, D.T. \& Milvae, R. (1988) The effects of exogenous-oxytocin on ovine corpus luteum function. J. Anim. Sci. Suppl. 1, 66, 385 (abstr.).

Sheldrick, E.L. \& Flint, A.P.F. (1985) Endocrine control of uterine oxytocin receptors in the ewe. $J$. Endocr. 106, 249-258.

Staples, R.E., McEntee, K. \& Hansel, W. (1961) Luteal function as related to pituitary and ovarian cytology and embryo development in the bovine. J. Dairy Sci. 44, 2049-2057.

Tsang, P.C.W., Walton, J.S. \& Hansel, W. (1990) Oxytocin-specific RNA, oxytocin and progesterone concentrations in corpora lutea of heifers treated with oxytocin. J. Reprod. Fert. 89, 77-84.

Wathes, D.C. (1989) Oxytocin and vasopressin in the gonads. Oxford Rev. Reprod. Biol. 11, 225-284.

Wathes, D.C. \& Swann, R.W. (1982) Is oxytocin an ovarian hormone? Nature, Lond. 297, 225-227. 
Wathes, D.C., Guldenaar, S.E.F., Swann, R.W., Webb, R., Porter, D.G. \& Pickering, B.T. (1986) A combined radioimmunoassay and immunocytochemical study of ovarian oxytocin production during the periovulatory period in the ewe. J. Reprod. Fert. $\mathbf{7 8}$, 167-183.

Wathes, D.C., Ayad, V.J., McGoff, S.A. \& Morgan, K.L. (1989) Effect of active immunization against oxytocin on gonadotropin secretion and the establishment of pregnancy in the ewe. J. Reprod. Fert. 86, 653-664.
Webb, R., Mitchell, M.D., Falconer, J. \& Robinson, J.S. (1981) Temporal relationships between peripheral plasma concentrations of oxytocin, progesterone and 13, 14-dihydro-15-keto prostaglandin $F_{2 u}$ during the oestrous cycle and early pregnancy in the ewe. Prostaglandins 22, 443-454.

Wilmut, I., Sales, D.I. \& Ashworth, C.J. (1985) The influence of variation in embryo stage and maternal hormone profiles on embryo survival in farm animals. Theriogenology 23, 107-119.

Received 17 August 1990 